\title{
INDICADORES ECONÔMICOS NO COMÉRCIO VAREJISTA DE FLORES: UM ESTUDO DE CASO
}

\author{
JOSÉ MATHEUS PEROSA ${ }^{1}$; JOÃO PAULO LOPES e LÍVIA MOURA SOUZA
}

\begin{abstract}
RESUMO
Estudos recentes têm mostrado uma mudança no comportamento do consumidor. O aumento da concorrência tem colocado questões novas sobre a competitividade, indicando a neces-sidade de uma abordagem sistêmica. A necessidade de transparência no âmbito do sistema coloca-se como dado importante à tomada de decisões pelos agentes econômicos que dele participam. Indicadores econômicos na floricultura são mais visíveis no lado produtivo, com possibilidade de mensuração dos custos de produção e margens obtidas no processo de comercialização. Na esfera da distribuição, a disponibilidade de dados e informações de custos e margens é mais difícil, tornando o mercado menos transparente. Este trabalho tem por objetivo uma análise de indicadores econômicos no comércio varejista de flores, como subsídio a trabalhos comparativos dos participantes do sistema produtivo. Para uma análise mais consistente no tempo, procedeu-se ao levantamento de informações do qüinqüênio 1995-2000, por meio de um estudo de caso do segmento varejista. Os dados mostram uma queda nas receitas, despesas e lucro bruto no período, indicativo do aumento da concorrência no setor. A margem de comercialização do varejo das principais flores comercializadas variou de 33 a $52 \%$, com média de $38 \%$. Os indicadores econômicos revelaram uma queda da lucratividade no período considerado.
\end{abstract}

Palavras-chave: flores, varejo, indicadores econômicos.

\section{ABSTRACT \\ Economics indicators in the retailer flowers market: a case study}

Recent studies have been showing a change in the consumer's behavior. The increase of the competition has been placing new subjects about the competitiveness, indicating the need of a system approach. The transparency relationship with the system is more important to the decision makers. Economics indicators in the flowers market are more available on the side of the production, with possibility of mensuration of the production costs and margins obtained in the commercialization process. Concerning of the distribution, the availability of information of costs and margins it is more difficult. The objective of this paper was an analysis of economics indicators in the retailer flowers market; furthermore this paper would be a subsidy to compare works of the different participants of the productive system. For a more consistent analysis along time, it was collect information of costs and margins of the period 1995-2000, through a case study of the retailers. The data show decrease in the income, expenses and gross profit in the period; these indicators point an increase of the competition in the sector. The margin of commercialization of the retail of the main flowers it varied from 33 to $52 \%$ with average $38 \%$. The economic indicators showed a decrease of the profitability in the considered period.

Key words: flowers, retail, economic indicators.

\footnotetext{
' Departamento de Gestão e Tecnologia Agroindustrial, Faculdade de Ciências Agronômicas - Unesp, Fazenda Experimental Lageado. Caixa Postal 237,18603-970 Botucatu (SP). E-mail: dede@fca.unesp.br
} 


\section{INTRODUÇÃO}

Estudos recentes têm mostrado uma mudança no comportamento do consumidor em relação às etapas da produção, processamento e distribuição de produtos de origem agrícola. Cada vez mais, aspectos relacionados à qualidade do produto são levados em consideração pelo consumidor.

Do lado da oferta, a abertura de mercados e respectivo aumento da concorrência, a necessidade de integração produtiva para o atendimento da qualidade exigida e a de agregação de valores na busca de maiores margens, colocam-se como questões relevantes à participação das empresas no mercado.

A aquisição de competitividade, individualmente e no âmbito de sistemas produtivos, requer uma postura que ultrapasse a tradicional preocupação com preços. A preocupação por qualidade implica a capacidade individual e o sistema produtivo em participar de um processo mais ou menos cooperativo e custoso. A fluidez do ambiente concorrencial provoca a necessidade de uma visão dinâmica de competitividade, ultrapassando a visão estática das vantagens adquiridas (FARINA, 1997).

A qualidade, e sua participação na aquisição de competitividade está diretamente relacionada ao grau de integração entre os agentes que participam do processo de produção, viabilizando condutas e comportamentos que se expressam em compromissos com o produto demandado pelo consumidor.

Tais compromissos são, no entanto, mais ou menos fortes em sistemas que adotam uma estratégia de ação que contemplem a participação nos resultados econômicos de todos os agentes.

Para as empresas e para os sistemas produtivos, o desafio não se restringe a produzir mais, melhor e barato, porém, usar ainda o conhecimento na definição de estratégias de ação e de avaliação das ações implementadas (QUELOPANA, 2001).

O segmento de flores e plantas ornamentais no Brasil se caracteriza pelo ambiente fortemente concorrencial. Até meados da década de 90 , a posição dos produtores era relativamente confortável, com mercado demandante (AKI, 2000b). Do lado da oferta, a integração de mercados regionais e a abertura externa aumentaram a competição, induzindo alguns segmentos a uma concorrência predatória. O aumento da concorrência, que se manifesta de forma intensa a partir de 1995, tem reestruturado o sistema produtivo em São Paulo: de acordo com AKI (2000b), “... os maiores produtores de São Paulo consolidaram-se em termos de volume e custo. Estabeleceram canais independentes de vendas e tem no preço sua principal ferramenta de competi-tividade. Para esses não interessa os mercados pequenos, onde a demanda pode ser atendida com qualidade diferenciada ...os pequenos produtores são os mais prejudicados."

Mesmo com o acirramento da concorrência, alguns autores ressaltam o grande potencial de crescimento e espaço no mercado de flores e plantas ornamentais. De acordo com CASTRO (1998), “...o consumo potencial é o dobro do consumo real hoje verificado", o que classificaria a floricultura como um mercado de demanda.

Indicadores econômicos na floricultura são mais visíveis no lado da produção, com possibilidade de mensuração dos seus custos e margens obtidas no processo de comercialização. Na esfera da distribuição, a disponibilidade de dados e informações de custos e margens é mais difícil, dificultando uma análise comparativa dos aspectos econômicos entre os agentes do sistema, tornando o mercado menos transparente.

Este trabalho tem por objetivo uma análise de indicadores econômicos no comércio varejista de flores, como subsídio a trabalhos comparativos dos diversos participantes do sistema produtivo.

\section{MATERIAL E MÉTODOS}

As informações sistematizadas de comercialização de flores referem-se a um estudo de caso realizado junto a estabelecimento comercial da cidade de Jundiaí (SP). Segundo levantamento do Veiling Holambra, o faturamento médio mensal de 750 estabelecimentos de varejo pesquisados foi de $\mathrm{R} \$ 9.500,00$ (AKI, 2000a). A floricultura pesquisada encontra-se pouco acima desse padrão de faturamento. Informações sobre vendas e estrutura 
das despesas, obtidas em floricultura semelhante à pesquisada, na vizinha cidade de Itatiba (SP), foram utilizadas como indicadores de consistência dos dados levantados. Coletaram-se, também, na empresa citada, preços de compra e venda do varejo das principais flores comercializadas. Trabalhou-se com dados agregados disponíveis no estabelecimento pesquisado, de porte médio, e que teve suas atividades iniciadas em 1994, participando, portanto, do processo de transformação mais incisivo que se observa no mercado de flores e plantas ornamentais a partir desse ano.

Os valores foram deflacionados pelo IGP-DI da FGV, tendo como mês de referência dezembro do ano 2000. Os dados discriminados de despesas foram disponibilizados apenas para 1995-97: também nesse caso, optou-se pela sua transformação em valores de dezembro de 2000.

Com base nos resultados obtidos no estudo de caso, elaboraram-se indicadores econômicos para avaliação de desempenho: despesa/receita, margem bruta/despesa e margem do varejo. A margem bruta corresponde à diferença entre receita e despesa. A do varejo é aqui representada como a relação, expressa em porcentagem, da margem bruta diante da receita obtida. Embora difira do cálculo tradicional da margem de comercialização do varejo, expressa como a relação entre a diferença de preços de compra e venda no varejo ante o preço do varejo, sua margem, calculada neste trabalho, constitui um indicador de resultado importante para avaliação de desempenho.
O cálculo da margem de comercia-lização do varejo foi possível apenas para outra floricultura, que não a do estudo de caso, sendo empregada como referência de análise.

\section{RESULTADOS E DISCUSSÃO}

3.1. Descrição do estabelecimento pesquisado Localiza-se em uma construção com diversos estabelecimentos comerciais geminados, na avenida principal da cidade. Tem área de, aproximadamente, $40 \mathrm{~m}^{2}$ para a exposição das flores, um banheiro, dois escritórios e uma copa. Situa-se na esquina, com estacionamento, boa apresentação visual, com arranjos e flores expostas na vitrine.

3.2. Esquema operacional - Trabalham no estabelecimento três pessoas da família do proprietário, em horários diferentes, entre 8 e 19 horas. Uma quarta pessoa, contratada, é responsável pelas entregas. São comercializadas flores de vaso, de corte, arranjos, buquês e objetos de enfeites. As vendas são feitas à vista ou a prazo com cheque prédatado e/ou cartão de crédito. A contabilidade é realizada por um escritório especializado. As flores são compradas de atacadista e, em alguns casos, diretamente do produtor.

\subsection{Evolução das receitas, despesas e margem} bruta - A Tabela 1 mostra um resumo das despesas e receitas no período de 1995-2000.

Tabela 1. Receita, despesa e margem bruta no período 1995/2000 (em reais) e índice $(1995=100)$

\begin{tabular}{|c|c|c|c|c|c|c|}
\hline \multirow{2}{*}{ Ano } & \multicolumn{2}{|c|}{ Receita } & \multicolumn{2}{|c|}{ Despesa } & \multicolumn{2}{|c|}{ Margem bruta } \\
\hline & $\mathrm{R} \$$ & Índice & $\mathrm{R} \$$ & Índice & $\mathrm{R} \$$ & Índice \\
\hline 1995 & $186.130,00$ & 100,0 & $147.903,00$ & 100,0 & $38.227,00$ & 100,0 \\
\hline 1996 & $181.199,00$ & 97,4 & $118.068,00$ & 79,8 & $63.130,00$ & 165,1 \\
\hline 1997 & $145.213,00$ & 78,0 & $96.647,00$ & 65,3 & $48.566,00$ & 127,0 \\
\hline 1998 & $133.901,00$ & 71,9 & $89.752,00$ & 60,7 & $44.149,00$ & 115,5 \\
\hline 1999 & $127.807,00$ & 68,7 & $88.311,00$ & 59,7 & $39.496,00$ & 103,3 \\
\hline 2000 & $100.555,00$ & 54,0 & $74.565,00$ & 50,4 & $25.990,00$ & 68,0 \\
\hline Média & \multicolumn{2}{|c|}{$145.801,00$} & \multicolumn{2}{|c|}{$102.541,00$} & \multicolumn{2}{|c|}{$43.260,00$} \\
\hline
\end{tabular}

Fonte: Levantamento de pesquisa. Valores em reais de dezembro de 2000, corrigidos mensalmente pelo IGP-DI / FGV. 
Tendo iniciado suas atividades no segundo semestre de 1994, após a implantação do Plano Real, o estabelecimento mostrou um crescimento da margem bruta nos dois primeiros anos, decrescendo a partir de então. A receita máxima anual, ocorrida em 1995, foi de R\$186.130,00, chegando em 2000 com o valor de $\mathrm{R} \$ 100.555,00$, o que representa uma queda de aproximadamente $46 \%$ em termos reais. As despesas também mostram um comportamento decrescente, com uma queda aproximada de 50\% entre o início e o fim do período considerado. A última coluna mostra a evolução da margem bruta, tomando como base 1995. Os valores alcançados indicam um comportamento decrescente a partir de 1996, ano do maior valor registrado: em relação ao ano 2000, verifica-se uma queda significativa, passando de $\mathrm{R} \$ 63.130,00$ para $\mathrm{R} \$ 25.990,00$.

Os resultados agregados estão de acordo com estudos que indicam um aumento da concorrência e dificuldades no aumento e/ou manutenção das margens a partir de meados da década passada.

A Tabela 2 mostra o comportamento da receita ao longo do período considerado.
A receita média mensal no período foi de $\mathrm{R} \$ 12.150,00$. Os dados mostram uma tendência de queda, passando de $\mathrm{R} \$ 15.511,00$ para $\mathrm{R} \$ 8.380,00$ entre os anos de ponta. Uma vez que se procedeu à correção monetária dos valores para efeito de análise e construção de indicadores, o resultado é mais contundente que aquele verificado sem esse procedimento. A última linha da Tabela 2 mostra a média mensal sem levar em conta os efeitos da inflação no período. Verifica-se, também, a tendência de queda da receita, mas de forma menos perceptível ao proprietário do estabelecimento, passando de $\mathrm{R} \$ 9.459,00$ para $\mathrm{R} \$ 7.980,00$ entre os anos de ponta.

A última coluna mostra o índice de variação mensal da receita em relação à média verificada no ano. Os meses de maior faturamento são os de maio, junho, setembro e dezembro, com um percentual de $43,8,13$ e $32 \%$ acima da média. Nesses meses, ocorrem festividades com maior venda, como Dia das Mães, Dia dos Namorados, Corpus Cristi, Dia da Secretária e Natal. Também nesse caso, os resultados seguem o padrão do comércio de flores em geral (CASTRO, 1998).

Tabela 2. Receita mensal, total e média (em reais) e índice médio mensal no período 1995-2000

\begin{tabular}{|c|c|c|c|c|c|c|c|c|c|}
\hline Ano & 1995 & 1996 & 1997 & 1998 & 1999 & 2000 & Total & Média & Índice \\
\hline 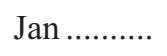 & $9.784,00$ & $18.398,00$ & $8.822,00$ & $9.482,00$ & $8.770,00$ & $6.947,00$ & $62.203,00$ & $10.367,00$ & 85 \\
\hline Fev ................. & $11.206,00$ & $10.400,00$ & $6.685,00$ & $7.524,00$ & $7.850,00$ & $8.775,00$ & $52.440,00$ & $8.740,00$ & 72 \\
\hline Mar .......... & $11.581,00$ & $15.988,00$ & $10.954,00$ & $11.230,00$ & $13.103,00$ & $9.820,00$ & $72.675,00$ & $12.112,00$ & 100 \\
\hline Abr ............. & $11.971,00$ & $12.473,00$ & $10.966,00$ & $9.917,00$ & $10.058,00$ & $7.202,00$ & $62.588,00$ & $10.431,00$ & 86 \\
\hline Mai .......... & $17.897,00$ & $20.946,00$ & $16.916,00$ & $16.013,00$ & $17.850,00$ & $14.548,00$ & $104.170,00$ & $17.362,00$ & 143 \\
\hline Jun .......... & $14.466,00$ & $16.931,00$ & $15.484,00$ & $11.913,00$ & $10.753,00$ & $9.431,00$ & $78.978,00$ & $13.163,00$ & 108 \\
\hline Jul ........... & $12.984,00$ & $11.003,00$ & $9.019,00$ & $10.453,00$ & $9.586,00$ & $7.448,00$ & $60.493,00$ & $10.082,00$ & 83 \\
\hline Ago .......... & $19.077,00$ & $12.810,00$ & $13.222,00$ & $9.686,00$ & $9.133,00$ & $6.949,00$ & $70.877,00$ & $11.813,00$ & 97 \\
\hline Set ................ & $16.766,00$ & $15.806,00$ & $14.969,00$ & $15.245,00$ & $10.612,00$ & $8.710,00$ & $82.109,00$ & $13.685,00$ & 113 \\
\hline Out .............. & $16.362,00$ & $14.309,00$ & $12.732,00$ & $9.160,00$ & $8.791,00$ & $6.450,00$ & $67.804,00$ & $11.301,00$ & 93 \\
\hline Nov .......... & $15.897,00$ & $14.857,00$ & $10.735,00$ & $9.019,00$ & $8.189,00$ & $5.869,00$ & $64.567,00$ & $10.761,00$ & 89 \\
\hline Dez........... & $28.138,00$ & $17.277,00$ & $14.709,00$ & $14.256,00$ & $13.113,00$ & $8.406,00$ & $95.899,00$ & $15.983,00$ & 132 \\
\hline $\operatorname{Média}^{1} \ldots$ & $15.511,00$ & $15.100,00$ & $12.101,00$ & $11.158,00$ & $10.651,00$ & $8.380,00$ & $72.900,00$ & $12.150,00$ & 100,0 \\
\hline Total ........ & $186.130,00$ & $181.199,00$ & $145.213,00$ & $133.901,00$ & $127.807,00$ & $100.555,00$ & $874.804,00$ & & \\
\hline Média $^{2} \ldots$ & $9.459,00$ & $10.156,00$ & $8.822,00$ & $8.471,00$ & $8.891,00$ & $7.980,00$ & & $8.963,00$ & \\
\hline
\end{tabular}

Fonte: Levantamentode pesquisa. Valores em R \$ de dezembro de 2000, corrigidos mensalmente pelo IGP-DI / FGV.

${ }^{1}$ Média mensal com correção monetária.

${ }^{2}$ Média mensal sem correção monetária. 
A Tabela 3 mostra o comportamento da despesa ao longo do período considerado.

A despesa média foi de $\mathrm{R} \$ 8.545,00$, apresentando uma variação $\mathrm{R} \$ 6.111,00$ entre as médias de 1995 e 2000 que foram os anos de, respectivamente, maior e menor despesas. A média das despesas durante o período acompanhou a queda das receitas. A redução do volume do estoque no estabelecimento, ocorrido nos primeiros anos de atividade, contribuiu para essa queda das despesas. A última linha da tabela mostra os valores de despesas médias no período sem a correção monetária: da mesma forma que nas receitas, pode-se observar uma redução menos pronunciada e certa estabilidade nos últimos três anos. Mensalmente, as maiores despesas seguem os meses de maiores vendas como maio, junho, setembro e dezembro, respondendo por $38,7 \%$ das despesas totais médias do período.

$\mathrm{Na}$ Tabela 4, encontra-se a discriminação das despesas no período de 1995 a 1997 com os valores já reajustados monetariamente.

A última coluna da tabela apresenta a participação de cada item de despesa em relação ao total médio. Os maiores valores de despesa referem- -se a compras de perecíveis (flores) e não perecíveis (embalagens, material de enfeite, vasos, etc.), com aproximadamente $47 \%$ do total. Outras despesas importantes correspondem aos salários e encargos, aluguel do imóvel, e mão-de-obra de terceiros referente ao entregador, com cerca de $27 \%$. Houve queda em alguns itens como salários e encargos, manutenção, marketing e impressos. A maior queda foi referente à compra de produtos não perecíveis, com redução de pouco mais de $\mathrm{R} \$ 10.000,00$ em vista da redução do estoque no estabelecimento. Outros itens como luz, aluguel e mão-de-obra de terceiros apresentaram alta.

Os dados coletados não permitem a elaboração de indicadores como a margem de comercialização do varejo, que representa a participação retida pelo mercado varejista do preço pago pelo consumidor. Dados coletados junto a uma empresa varejista em Itatiba (SP) foram utilizados para elaboração da Tabela 5, como referência desse indicador. As principais flores comercializadas nessa empresa são as mesmas do estudo de caso. Os valores da margem do varejo encontrados para as diversas flores variaram de 30 a 52\%, com média de 38\%.

Tabela 3. Despesa mensal, total e média (em reais) e índice médio mensal no período 1995-2000

\begin{tabular}{|c|c|c|c|c|c|c|c|c|c|}
\hline Ano & 1995 & 1996 & 1997 & 1998 & 1999 & 2000 & Total & Média & Índice \\
\hline Jan.. & $11.250,00$ & $12.161,00$ & $7.303,00$ & 6.640 & $6.659,00$ & $6.541,00$ & $50.553,00$ & $8.425,00$ & 99 \\
\hline Fev ... & $7.692,00$ & $8.616,00$ & $6.325,00$ & $6.445,00$ & $6.215,00$ & $5.932,00$ & $41.225,00$ & $6.871,00$ & 80 \\
\hline Mar ......... & $12.811,00$ & $8.402,00$ & $6.761,00$ & $6.979,00$ & $8.140,00$ & $6.368,00$ & $49.460,00$ & $8.243,00$ & 96 \\
\hline Abr. & $9.208,00$ & $11.501,00$ & $7.030,00$ & $8.679,00$ & $6.973,00$ & $5.335,00$ & $48.726,00$ & $8.121,00$ & 95 \\
\hline Mai ......... & $15.319,00$ & $12.360,00$ & $12.166,00$ & $9.152,00$ & $11.300,00$ & $7.799,00$ & $68.097,00$ & $11.349,00$ & 133 \\
\hline Jun .......... & $17.006,00$ & $8.772,00$ & $9.232,00$ & $6.631,00$ & $7.369,00$ & $7.631,00$ & $56.641,00$ & $9.440,00$ & 110 \\
\hline Jul ............ & $9.881,00$ & $8.603,00$ & $6.715,00$ & $7.201,00$ & $5.759,00$ & $5.965,00$ & $44.124,00$ & $7.354,00$ & 86 \\
\hline Ago .......... & $10.401,00$ & $9.104,00$ & $8.226,00$ & $7.340,00$ & $6.980,00$ & $5.539,00$ & $47.590,00$ & $7.932,00$ & 93 \\
\hline Set ................ & $10.918,00$ & $8.600,00$ & $8.383,00$ & $7.388,00$ & $7.407,00$ & $6.571,00$ & $49.267,00$ & $8.211,00$ & 96 \\
\hline Out .......... & $12.402,00$ & $10.053,00$ & $8.825,00$ & $8.466,00$ & $7.412,00$ & $6.096,00$ & $53.253,00$ & $8.875,00$ & 104 \\
\hline Nov .......... & $12.204,00$ & $9.250,00$ & $8.255,00$ & $7.268,00$ & $6.156,00$ & $5.598,00$ & $48.730,00$ & $8.122,00$ & 95 \\
\hline Dez .......... & $18.811,00$ & $10.646,00$ & $7.428,00$ & $7.564,00$ & $7.943,00$ & $5.190,00$ & $57.581,00$ & $9.597,00$ & 112 \\
\hline Média $^{1}$ & $12.325,00$ & $9.839,00$ & $8.054,00$ & $7.479,00$ & $7.359,00$ & $6.214,00$ & $51.270,00$ & $8.545,00$ & 100,0 \\
\hline Total........ & $147.903,00$ & $118.068,00$ & $96.647,00$ & $89.752,00$ & $88.311,00$ & $74.565,00$ & $615.246,00$ & & \\
\hline Média $^{2} \ldots . . .$. & $7.507,00$ & $6.697,00$ & $5.517,00$ & $5.678,00$ & $6.139,00$ & $5.926,00$ & $37.464,00$ & $6.244,00$ & \\
\hline
\end{tabular}

Fonte: Levantamento de pesquisa. Valores em reais de dezembro de 2000, corrigidos mensalmente pelo IGP-DI / FGV.

${ }^{1}$ Média mensal com correção monetária.

${ }^{2}$ Média mensal sem correção monetária. 
Tabela 4. Discriminação das despesas no período de 1995 a 1997, em reais de dezembro de 2000

\begin{tabular}{|c|c|c|c|c|c|c|}
\hline Ítem de despesa & 1995 & 1996 & 1997 & Total & Média & $\%$ \\
\hline Água .. & 209,00 & 432,00 & 471,00 & $1.113,00$ & 371,00 & 0,3 \\
\hline Luz ...... & 852,00 & $1.426,00$ & $1.285,00$ & $3.563,00$ & $1.188,00$ & 1,0 \\
\hline 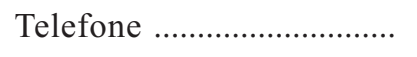 & $1.071,00$ & $1.110,00$ & 906,00 & $3.088,00$ & $1.029,00$ & 0,9 \\
\hline Salário + Encargos ............ & $11.862,00$ & $10.075,00$ & $5.978,00$ & $27.916,00$ & $9.305,00$ & 7,7 \\
\hline 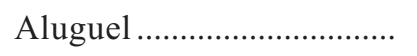 & $15.201,00$ & $17.710,00$ & $18.190,00$ & $51.101,00$ & $17.034,00$ & 14,1 \\
\hline Impostos & $2.770,00$ & $3.060,00$ & $2.164,00$ & $7.994,00$ & $2.665,00$ & 2,2 \\
\hline Manutenção ........................ & $12.422,00$ & $9.149,00$ & $4.623,00$ & $26.194,00$ & $8.731,00$ & 7,2 \\
\hline 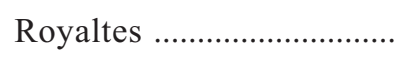 & $11.946,00$ & $3.653,00$ & $3.033,00$ & $18.633,00$ & $6.211,00$ & 5,1 \\
\hline 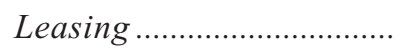 & 0,00 & $1.876,00$ & $2.842,00$ & $4.718,00$ & $1.573,00$ & 1,3 \\
\hline Marketing ............................. & $9.520,00$ & $5.569,00$ & $2.509,00$ & $17.598,00$ & $5.866,00$ & 4,9 \\
\hline Compras perecíveis ........... & $42.508,00$ & $38.951,00$ & $31.406,00$ & $112.865,00$ & $37.622,00$ & 31,1 \\
\hline Compras não perecíveis .... & $28.794,00$ & $15.421,00$ & $15.143,00$ & $59.358,00$ & $19.786,00$ & 16,4 \\
\hline M.O.Terceiros ........................ & $5.005,00$ & $6.673,00$ & $6.183,00$ & $17.860,00$ & $5.953,00$ & 4,9 \\
\hline 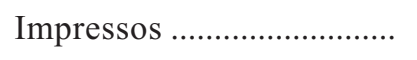 & $5.743,00$ & $1.353,00$ & $1.605,00$ & $8.701,00$ & $2.900,00$ & 2,4 \\
\hline 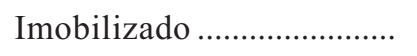 & 0,00 & $1.609,00$ & 134,00 & $1.744,00$ & 581,00 & 0,5 \\
\hline 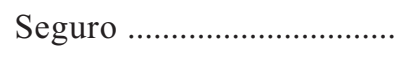 & 0,00 & 0,00 & 174,00 & 174,00 & 58,00 & 0,0 \\
\hline 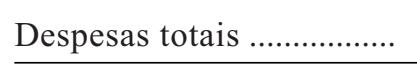 & $147.903,00$ & $118.068,00$ & $96.647,00$ & $362.618,00$ & $120.873,00$ & 100,0 \\
\hline
\end{tabular}

Fonte: Levantamento de pesquisa.

Valores em reais de dezembro de 2000, corrigidos mensalmente pelo IGP-DI / FGV.

Tabela 5. Preço de compra e venda, margem de comercialização do varejo e parcela retida pelos produtores das principais plantas comercializadas

\begin{tabular}{|c|c|c|c|c|}
\hline Flor & Preço compra & Preço venda & $\begin{array}{l}\text { Margem com. } \\
\text { varejo }\end{array}$ & $\begin{array}{l}\text { Parcela retida } \\
\text { pelo produtor }\end{array}$ \\
\hline & \multicolumn{2}{|c|}{ R\$/unidade } & $\%$ & $\%$ \\
\hline 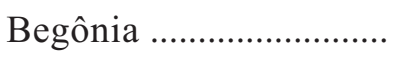 & 3,33 & 7,00 & 52,43 & 47,57 \\
\hline 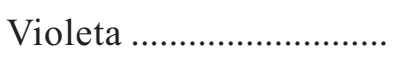 & 1,00 & 1,50 & 33,33 & 66,67 \\
\hline 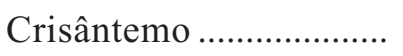 & 1,66 & 3,00 & 44,67 & 55,33 \\
\hline Minicrisântemo ............... & 1,00 & 1,50 & 33,33 & 66,67 \\
\hline Lírio-da-Paz .................... & 3,50 & 5,00 & 30,00 & 70,00 \\
\hline Média .............................. & & & 38,75 & 61,25 \\
\hline
\end{tabular}

Fonte: Levantamento de pesquisa - floricultura de Itatiba (SP).

Valores em reais de dezembro de 2000.

Tabela 6. Indicadores econômicos

\begin{tabular}{lrrrrrrr}
\hline Ítens/Ano & 1995 & 1996 & 1997 & 1998 & 1999 & 2000 & Média \\
\hline Despesa/receita (em \%) .......... & 79,9 & 66,0 & 62,5 & 67,0 & 69,1 & 74,2 & 69,8 \\
Margem bruta/despesa (\%) ...... & 25,2 & 51,6 & 59,9 & 49,2 & 44,7 & 34,9 & 44,2 \\
Margem do varejo (\%) ............ & 20,1 & 34,0 & 37,5 & 33,0 & 30,9 & 25,8 & 30,2 \\
\hline
\end{tabular}


As maiores margens verificadas são para a comercialização de begônias e crisântemos, com 52 e $44 \%$ respectivamente. Nessa margem estão incluídas todas as despesas decorrentes do processo de comercialização no varejo, constante da Tabela 4, inclusive as perdas verificadas (não consideradas na mesma), assim como o lucro da atividade. Dado que as flores comercializadas pela floricultura em questão são adquiridas em quase sua totalidade junto a produtores, o percentual restante representa a parcela retida por eles. Assim, em média, a parcela retida pelos produtores representa $62 \%$ do preço pago pelo consumidor. Essa participação não representa o lucro, uma vez que os custos de produção e comercialização até o varejo estão aí incluídos.

A Tabela 6 mostra os principais indicadores econômicos elaborados a partir das tabelas anteriores.

Os dados mostram um crescimento inicial das margens retidas ante as despesas na atividade, e uma tendência de queda a partir de 1997. O mesmo ocorre em relação à margem do varejo, com crescimento inicial e posterior queda.

Esses dados são indicativos de uma queda da lucratividade e podem estar relacionados com aumento da concorrência. Informações de técnicos ligados ao setor confirmam esse indicativo. Esse aumento na concorrência se deve ao surgimento de novos pontos de vendas, como supermercados, garden centers e mesmo abertura de novas floriculturas e/ou adaptação das já existentes.

\section{CONCLUSÕES}

1. Observou-se uma queda na receita, despesa e margem retida pela empresa. Estudos apontam esse resultado ligado a aumento da concorrência no mercado varejista de flores.

2. Essa queda na comercialização pode também estar relacionada a uma reestruturação do mercado a partir de 1995. O mercado tem favorecido os maiores produtores e os grandes revendedores que conseguem a aquisição de produtos de qualidade a um preço baixo pelo maior volume de comercialização.
3. As maiores receitas na comercialização de flores correspondem às datas especiais como Dia das Mães, Dia dos Namorados, Corpus Christi, Dia da Secretária e Natal, as quais correspondem a, aproximadamente, $40 \%$ das receitas do ano. Esses dados enfatizam esse mercado como sendo de demanda, fundamentado em picos de venda, indicando um potencial de comércio pouco explorado.

4. As maiores despesas do varejista estão na aquisição de flores e plantas ornamentais e seus insumos de venda. Melhor estruturação na cadeia permitiria ao varejista reduzi-las, repassando-lhe maior poder de compra. Umas das saídas do varejista seria a compra direta dos produtos ou manter uma relação de fidelidade com o produtor/atacadista que resultasse em maiores prazos de pagamentos e descontos.

5. Dado que as informações são provenientes de um estudo de caso, as conclusões acima necessitam de comprovação de outros estudos para maior grau de generalização.

\section{LITERATURA CITADA}

AKI, A. Pesquisa sobre perfil do varejo e seus gargalos. Mensagem recebida por dede@fca.unesp.br em 2000 a.

AKI, A. O mercado de flores se GLOBRASILIZOU. Mensagem recebida por dede@fca.unesp.br em 2000 b.

CASTRO, C.E.F. Cadeia produtiva de flores e plantas ornamentais. Rev. Bras. Hortic. Ornam., Campinas, v.4, n.1/2, 1998. p.1-46.

FARINA, E.M.M.Q. Abordagem sistêmica dos negócios agroindustriais e a economia dos custos de transação. In: FARINA, E.M.M.Q.; AZEVEDO, P.F. \& SAES, M.S.M. (Orgs.) Competitividade: mercado, estado e organizações. São Paulo: Singular, 1997. p.165-176.

QUELOPANA, E. M. Um estudo sobre a ralação entre o conhecimento e a qualidade de decisão. Boletim do Núcleo de Gestão Tecnológica da Universidade de São Paulo, ano VIII, n. 25, Jan./Fev./Mar., 2001. p.3. 